\title{
MONITORAMENTO LIMNOLÓGICO DE AMBIENTES DA RESERVA PARTICULAR DO PATRIMÔNIO NATURAL (RPPN) FOZ DO RIO AGUAPEÍ
}

\author{
Renato Franco Rodrigues ${ }^{1}$, Yuri Comparato Moskovitz ${ }^{1}$, Renata Ribeiro de Araújo ${ }^{2}$ \\ ${ }^{1}$ Curso de Engenharia Ambiental da Universidade Estadual Paulista - UNESP - Presidente Prudente. ${ }^{2}$ Docente da \\ Universidade Estadual Paulista - UNESP - Presidente Prudente. E-mail: reee.fr@hotmail.com
}

\section{RESUMO}

O monitoramento de variáveis limnológicas foi realizado através de amostragens semestrais, durante um ciclo sazonal completo, de oito ambientes da Reserva Particular do Patrimônio Natural (RPPN) Foz do Rio Aguapeí. Em campo, através de aparelhos digitais portáteis da marca Hanna, foram amostradas as variáveis oxigênio dissolvido (OD), $\mathrm{pH}$, condutividade elétrica (CE), nitrato ( $\mathrm{N}$ $\mathrm{NO}_{3}$ ), temperatura da água ( $\mathrm{T}$ ), turbidez (Turb) e $\mathrm{N}$-amoniacal $\left(\mathrm{N}-\mathrm{NH}_{4}\right)$. De acordo com protocolos laboratoriais foram determinadas as variáveis clorofila $a$, material em suspensão total, fósforo dissolvido, fósforo reativo solúvel, fósforo total e nitrogênio Kjeldahl. A análise de componentes principais (ACP) foi aplicada aos resultados com o objetivo de reduzir a dimensionalidade dos dados e avaliar padrões na ordenação quanto aos diferentes ambientes (ambientes lênticos e ambientes lóticos) e, por fim, os diferentes períodos amostrados. Os resultados revelaram que os ambientes lênticos possuem maior carga orgânica quando comparados com os ambientes lóticos (rios Paraná e Aguapeí).

Palavras-chave: monitoramento limnológico; rio Paraná; rio Aguapeí

\section{I - INTRODUÇÃO E OBJETIVOS}

A Reserva Particular do Patrimônio Natural (RPPN) Foz do Rio Aguapeí/Brasil encontra-se no alto rio Paraná e faz divisa com o estado do Mato Grosso do Sul, abrangendo os municípios de Castilho (SP), São João do Pau d'Alho (SP) e Paulicéia (SP), é banhada pelos rios Paraná e Aguapeí e totaliza uma área de 13.953,79 hectares. A reserva apresenta grandes extensões de várzeas e uma fauna adaptada aos ciclos de cheia e seca.

A área possui características peculiares e um inegável potencial genético. Além disso, poderá constituir um corredor ecológico conectando diferentes unidades de conservação, como por exemplo, o Parque Estadual do Aguapeí (SP) e Parque Estadual do Rio do Peixe (SP), reduzindo a fragmentação, mantendo ou restaurando a conectividade da paisagem e facilitando o fluxo genético entre as populações.

Por se tratar de um processo de criação de uma Unidade de Conservação (UC), é necessário, por parte do proprietário, cumprir as exigências contidas na Lei № 9.985/2000 que institui o Sistema Nacional de Unidades de Conservação da Natureza. Uma das exigências, contida no Art. 27 §1으, diz que as Unidades de Conservação devem dispor de um Plano de Manejo. De 
acordo com a lei entende-se como Plano de Manejo um documento técnico, no qual, com fundamento nos objetivos gerais de uma Unidade de Conservação, é estabelecido o seu zoneamento e as normas que devem presidir o uso da área e o manejo dos recursos naturais.

O Plano de Manejo tem como objetivo principal compreender e apresentar o conjunto de ações necessárias para a gestão e uso sustentável dos recursos naturais em qualquer atividade no interior da RPPN e em áreas do entorno dela de modo a conciliar, de maneira adequada e em espaços apropriados, os diferentes tipos de usos com a conservação da biodiversidade.

Para o alcance deste objetivo é essencial o conhecimento da dinâmica do ecossistema, os processos naturais e as interferências antrópicas positivas ou negativas que o influencia ou o define, considerando os usos que o homem faz do território, analisando os aspectos pretéritos e os impactos atuais ou futuros de forma a elaborar meios para conciliar o uso dos espaços com os objetivos de criação da Unidade de Conservação. Sendo assim o diagnóstico ambiental é imprescindível para obtenção desta dinâmica.

Segundo o Roteiro Metodológico de Planejamento do Instituto Brasileiro do Meio Ambiente e dos Recursos Naturais Renováveis (IBAMA), publicado em 2002, na elaboração do diagnóstico ambiental do Plano de Manejo da UC deve-se apresentar temas obrigatórios, como a Limnologia, e este deve conter itens mínimos, como por exemplo, elaborar estudos das características físico-químicas dos ambientes lênticos e lóticos, assim como as interferências antrópicas que possam tê-los afetado.

Diante do exposto, o presente estudo propõe o monitoramento limnológico sitemático de ambientes da Reserva Particular do Patrimônio Natural (RPPN) "Foz do Rio Aguapeí" e espera-se que seus resultados permitam verificar as oscilações apresentadas pelos ambientes aquáticos frente às alterações naturais ou antrópicas, no tempo e no espaço.

Pretende-se ainda que o monitoramento limnológico seja uma ferramenta que possa ser utilizada para o desenvolvimento de estratégias próprias para o planejamento ordenado das ações a serem inseridas nestas áreas a fim de garantir a proteção dos recursos naturais nelas existentes e a consecução dos benefícios indiretos de ordem ecológica, econômica, científica e social, dela advindos.

\section{III - METODOLOGIA}

Para o desenvolvimento da presente pesquisa foi realizada revisão bibliográfica sobre a área de estudo e sobre os temas relacionados a esta pesquisa, como monitoramento limnológico, 
teorias ecológicas de ambientes aquáticos, planície de inundação, bacia hidrográfica, plano de manejo, reservas particulares, unidades de conservação e legislação ambiental.

As oito seções onde foram amostradas as variáveis limnológicas compreenderam ambientes lênticos e lóticos da Reserva Particular do Patrimônio Natural (RPPN) Foz do Rio Aguapeí (figura 1). As seções foram escolhidas baseadas em análise prévia das unidades geomorfológicas da planície fluvial dentro da RPPN e em acessibilidade aos ambientes.

O monitoramento limnológico foi realizado através de amostragens semestrais, na superfície das seções amostrais. O monitoramento foi efetuado durante um ciclo sazonal completo, com a intenção de se observar às variações limnológicas para as diferentes épocas do ano.

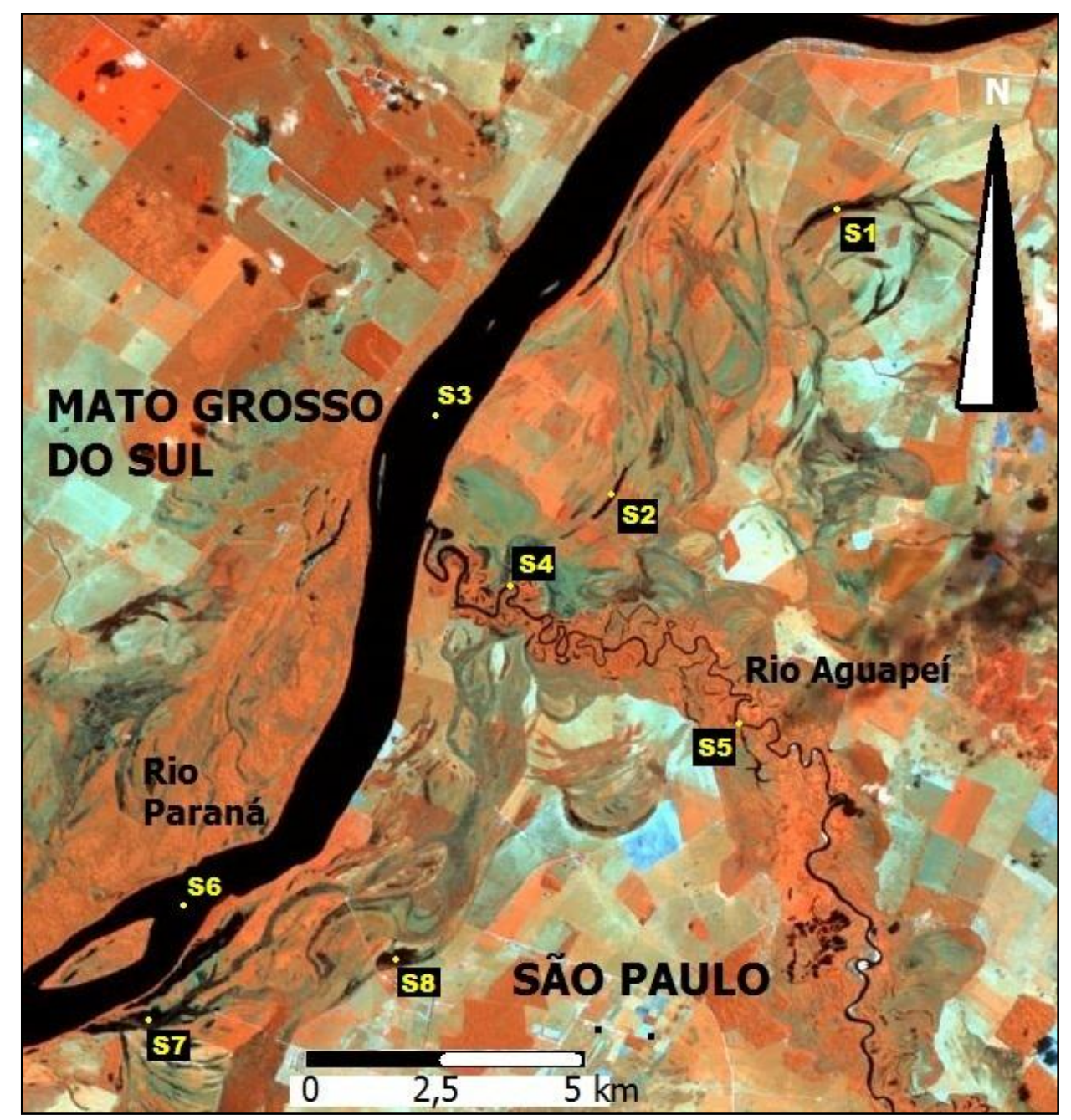

Figura 1. Seções de amostragem limnológica na Reserva Particular do Patrimônio Natural (RPPN) Foz do Rio Aguapeí. 
As variáveis limnológicas amostradas em campo foram o oxigênio dissolvido (OD), pH, condutividade elétrica (CE), temperatura da água ( $T$ ), turbidez (Turb). Estas variáveis foram amostradas através de aparelhos digitais portáteis.

Para o desenvolvimento dos protocolos laboratoriais, amostras de água foram obtidas nas seções amostrais com uma garrafa do tipo "Van Dorn" e preservadas em caixas de isopor, armazenadas em frascos de polietileno (5L).

No laboratório amostras de águas foram filtradas em membranas Whatman GF/C, e os filtros armazenados em freezer a $-20^{\circ} \mathrm{C}$ para posterior determinação das concentrações de clorofila $a$ de acordo com Golterman et al. (1978). Ainda no laboratório, amostras de águas foram filtradas em membranas Whatman GF/C, previamente calcinadas, e os filtros armazenados em freezer a $-20^{\circ} \mathrm{C}$ para posterior determinação das concentrações de material em suspensão total de acordo com Wetzel \& Likens (1991). A água filtrada também foi preservada em freezer a $-20^{\circ} \mathrm{C}$, em frascos de polietileno $(500 \mathrm{ml})$, para posterior determinação das formas dissolvidas de fósforo dissolvido e fósforo reativo solúvel. Da mesma forma, a água não filtrada foi preservada em freezer a $-20^{\circ} \mathrm{C}$, em frascos de polietileno $(500 \mathrm{ml})$, para posterior determinação das concentrações de fósforo totais.

As membranas GF/C foram analisadas por gravimetria para determinação das concentrações de material em suspensão de acordo com Wetzel \& Likens (1991). As frações de fósforo total e de fósforo dissolvido foram quantificadas após a digestão, na presença de um catalisador, em autoclave e posterior reação com adição de reagente misto (molibdato de amônia, tartarato de antimônio e potássio e ácido ascórbico) e leitura em espectrofotômetro a $882 \mathrm{~nm}$ (MACKERETH et al., 1978). O fósforo reativo solúvel ou orto-fosfato também foi obtido após reação com molibdato de amônia, tartarato de antimônio e potássio e ácido ascórbico e posterior leitura em espectrofotômetro a 882 nm (MACKERETH et al., 1978). O nitrogênio Kjeldahl foi quantificado de acordo com metodologia descrita em APHA (2005).

O N-amoniacal foi analisado de acordo com o descrito por Mackereth et al. (1978). A quantificação de $\mathrm{N}$ - nitrato $\left(\mathrm{N}-\mathrm{NO}_{3}\right)$, foi realizada de acordo com descrito por Giné et al. (1980), em Zagatto et al. (1981).

Os resultados do monitoramento das variáveis limnológicas foram tabulados em planilhas do Microsoft Excel e pacote Statistica for Windows. 
Para avaliação da amplitude de variação dos parâmetros limnológicos foi considerada a estatística descritiva das variáveis limnológicas amostradas com o uso do pacote Statistica for Windows.

Dentre as diversas técnicas de ordenação, a análise de componentes principais (ACP) foi aplicada, utilizando o pacote Statistica for Windows, com o objetivo de reduzir a dimensionalidade dos dados e avaliar padrões na ordenação quanto aos diferentes ambientes (ambientes lênticos, rio Paraná e rio Aguapeí) e, por fim, os diferentes períodos amostrados.

Os valores dos parâmetros limnológicos, exceto os do pH, foram log-transformados (base dez), para linearizar as relações e reduzir o efeito de valores elevados. Para avaliar os eixos a serem retidos para interpretação, utilizou-se o modelo de "broken-stick" (Jackson, 1993).

\section{IV - RESULTADOS}

A ACP resumiu o conjunto das variáveis ambientais escolhidas para o estudo. Utilizando o modelo de "broken-stick", os componentes principais 1 e 2 foram significativos e, portanto, retidos para a interpretação dos dados limnológicos. Estes dois componentes explicaram 44,5\% (CP1 $=29,3 \%$ e CP2 $=15,2 \%)$ da variabilidade total dos dados (figura 2 ).

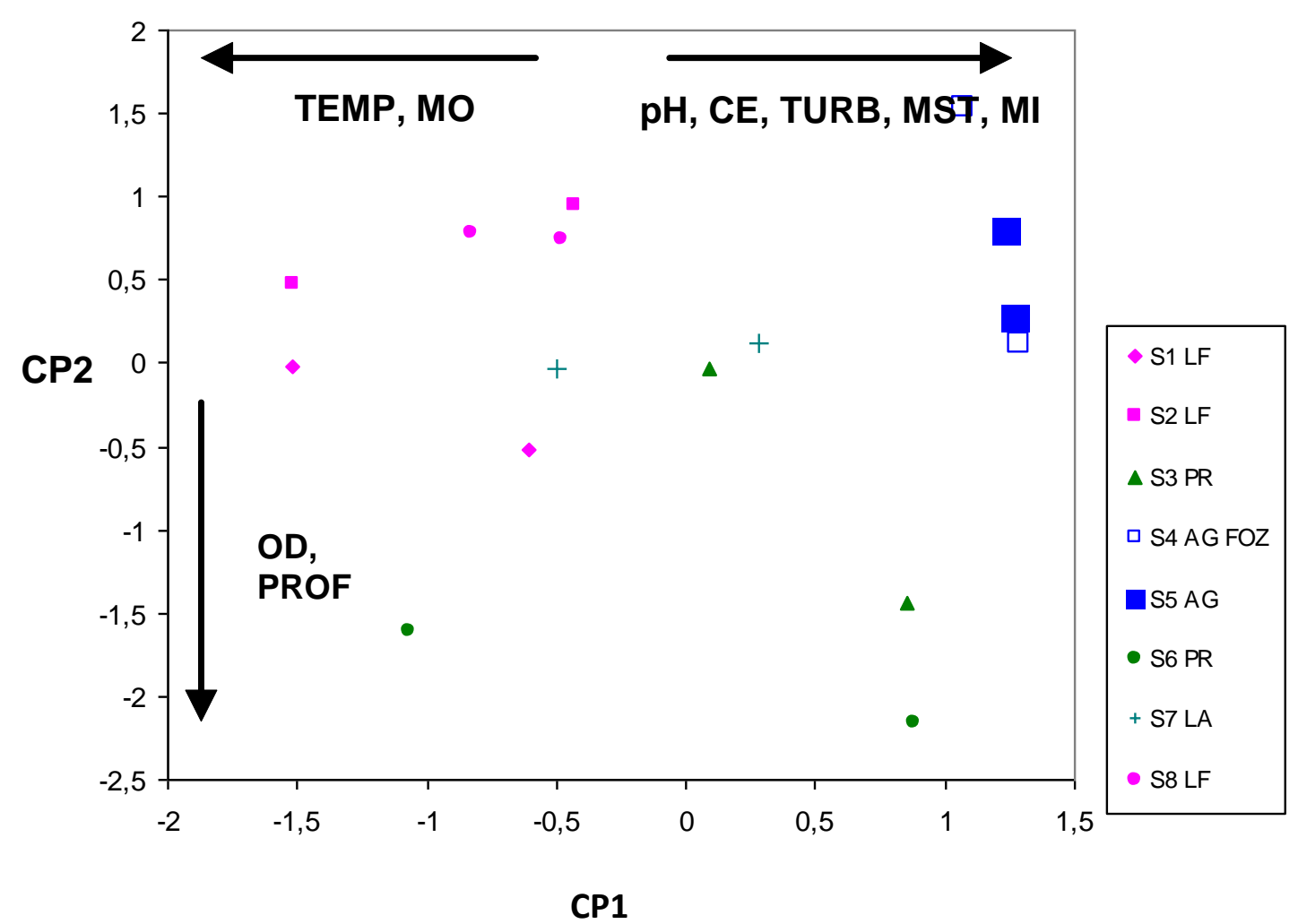

Figura 2. Resultado da Análise de Componentes Principais: ordenamento espacial. 
As variáveis positivamente correlacionadas com o componente principal 1 , foram a turbidez, material em suspensão total, material em suspensão total inorgânico, pH e condutividade elétrica. Por outro lado, a temperatura e o material em suspensão total orgânico correlacionou-se negativamente com o componente principal 1 . O componente principal 2 foi mais correlacionado, de forma negativa, pelo oxigênio dissolvido e profundidade.

\section{V - DISCUSSÃO}

Analisando estes resultados pôde-se observar que os ambientes lênticos possuem maior carga orgânica quando comparados com os resultados dos rios Paraná e Aguapeí, ambientes lóticos. Esta variabilidade pode estar relacionada ao fato dos ambientes lênticos serem ambientes de um sistema rio-planície de inundação. Provavelmente esta carga está associada a uma característica típica que é a alta produção de matéria orgânica em ambientes lênticos por diversas espécies de macrófitas aquáticas e anfíbias.

Estes resultados são corroborados por outras pesquisas limnológicas realizadas em ambientes lênticos de sistemas rios-planície de inundação (Bini, 1996; Rocha, 2003).

Os resultados mostraram ainda que o rio Aguapeí possui maior carga inorgânica em comparação com o rio Paraná. Este resultado pode estar relacionado ao fato de que o rio Paraná possui uma cascata de reservatórios (Agostinho et al., 2007, 2008), havendo, portanto, a sedimentação do material em suspensão nos reservatórios, o que não ocorre com o rio Aguapeí.

\section{VI - CONCLUSÃo}

Conclui-se que é possível predizer elementos fundamentais para a caracterização e dinâmica dos ecossistemas aquáticos, através de variáveis que expressam fatores chaves locais.

O modelo criado para a predição da condutividade elétrica, envolvendo alguns fatores independentes, como a matéria inorgânica, matéria orgânica e a turbidez, apresentou um poder de predição considerável. Seu potencial de uso também foi confirmado pelo êxito da validação independente.

\section{VII - REFERÊNCIAS}

Agostinho, A. A., L. C. Gomes, F. M. Pelicice. 2007. Ecologia e Manejo de Recursos Pesqueiros em Reservatórios do Brasil. Maringá, Eduem, 501 p. 
Agostinho, A. A., F. M. Pelicice, L. C. Gomes. 2008. Dams and the fish fauna of the Neotropical region: impacts and management related to diversity and fisheries. Brazilian Journal of Biology 68(4, Suppl.): 1119-1132. http://dx.doi.org/10.1590/S1519-69842008000500019

BINI, L. M., 1996. Influência do pulso de inundação nos valores de fitomassa do três espécies de macrófitas aquáticas na planície de inundação do alto rio Paraná. Arq. Biol. Tecnol. 39(3): 715721.

GOLTERMAN, H. L.; CLYMO, R. S. \& OHNSTAD, M. A. M., 1978. Methods for physical and chemical analysis of freshwaters. IBP Handbook no 8, 2a ed. Oxford, Blackwell Scient. Publ. 315 pp.

JACKSON, D., 1993. Stopping rules in principal component analysis: a comparison of euristical and statistical approaches. Ecology, 74, 2204-2214. http://dx.doi.org/10.2307/1939574

JOHNSON, L.J.; RICHARDSON, W.B.; NAIMO, T.J., 1995. Past, Present, and Future Concepts in Large River Ecology. BioSciece, 45. N.3., 134-141 pp.

JUNK, W.J.; BAYLEY, P.B.; SPARKS, R.E., 1989. The Flood Pulse Concept in River-Floodplain Systems. In: D.P. Dodge (Ed) Proceedings of the International Large River Symposium. Can. Spec. Public. Fish. Aquat. Sci., 106. 110-127 pp.

MACKERETH, F.Y.H., HERON, J.G.; TALLING, J., 1978. Water analysis: some revised methods for limnologists. Fresh. biological associat. publ. 36. 120 p.

ROCHA, R.R. de A., 2003. Limnologia Comparativa e Preditiva de Rios e Lagoas da Planície de Inundação do Alto Rio Paraná (PR/MS - Brasil). PEA/UEM, Maringá-PR. Tese de Doutoramento, inédito. $86 \mathrm{p}$.

WETZEL, R.G.; LIKENS, G.E., 1991. Limnological Analysis. 2 ed. New York: Spring Verlag. 